\title{
In-Cylinder Gas Exchange Control Process for Maximizing Fuel CONVERSION EFFICIENCY
}

\author{
Fábio de Castro Radicchi ${ }^{1}$, Bruno Vieira Silva ${ }^{1.2}$, José Guilherme Coelho Baêta ${ }^{1.3}$ \\ Fabrício José Pacheco Pujatti ${ }^{1.4}$, Carlos Fernando Mendes ${ }^{2}$, Gustavo Santos Lopes ${ }^{2.1}$, Paulo \\ César de Ferreira Gomes ${ }^{2.3}$ \\ ${ }^{1}$ Mobility Technology Center - Federal University of Minas Gerais \\ ${ }^{2}$ Robert Bosch Ltda
}

\begin{abstract}
E-mails: fabioradicchi@gmail.com, bruno.vieira.94@gmail.com, baeta@ demec.ufmg.br, pujatti@demec.ufmg.br, Carlos.Mendes2@br.bosch.com, external.Gustavo.Lopes@br.bosch.com, paulo.gomes@br.bosch.com
\end{abstract}

\begin{abstract}
The use of exhaust gas recirculation in internal combustion engines, obtained by means of variable valve timing techniques, has represented a good alternative to reduce in-cylinder gas emission and the specific fuel consumption, consequently improving thermal efficiency. The control of valves opening and closing times, especially when keeping some overlapping, may permit the residual gases trapping, what makes the cylinder temperatures lower and reduce engine-out emissions, mainly of nitrogen oxides. Besides that, these techniques allow load control, what can eliminate the necessity of throttling and hence pumping losses. Based on this, this paper presents an analysis of the use of variable valve timing focused on trapping some residual gases in a spark ignition engine. It has been used a four valve Single Cylinder Research Engine - SCRE with direct injection. It was adopted a volumetric ratio equal to $15: 1$, an engine speed of $2500 \mathrm{rpm}$ and the ethanol as fuel. Valves timing were changed taking into account the maximum fraction of exhaust gases which could be used without compromising mixture inflammability. Changes in performance were analyzed and the importance of controlling the amount of recycled exhaust gases was finally evidenced.
\end{abstract}

\section{INTRODUCTION}

Variable valve actuation systems have been increasingly studied due to the amount of benefits they may provide and their flexibility. This technology allows different configurations according to the operating conditions of the engine and the expected performance results, since it allows the control of the valve lift and timing whenever it is desired, which can contribute to the engine performance.

The increasing or decreasing of valve lift duration and its timing is associated with the Miller cycle or the Atkinson cycle: the early inlet valve closing (EIVC) is related to the Miller cycle and the late inlet valve closing (LIVC) to the Atkinson cycle. Both strategies are shown to improve engine thermal efficiency, reduce pumping losses and lower heat transfers [1]. 
Some studies also presented improvements related to NOx and soot emissions because of the utilization of the VVT mechanism for a wide range of engine speeds and loads [2]. There is still a problem related to $\mathrm{HC}$ emissions while the catalytic converter is not warm yet, but the use of strategies as low lift for fuel atomization and overlap control can avoid fuel adhesion to cylinder walls and consequently improve combustion by reducing the amount of unburned fuel [3].

The EIVC results in pumping losses, but the LIVC minimizes heat losses and it results in a lower temperature at the end of compression, which can be a benefit at higher loads to reduce knock [4]. However, when using Atkinson and Miller operation strategies, this lower temperature at the end of compression can reduce mixture temperature and result in a poor combustion. [5]

Although the EIVC and LIVC methods are known to reduce pumping work and improve fuel consumption, it is shown that each strategy can cause heat losses [6]. However, the LIVC when compared to EIVC reduces the turbulence conversion into heat and presents less disadvantages due to turbulence at ignition timing [7].

For E22 and E100 studies have shown that Atkinson and Miller operation cycle have less pumping losses than when closing the intake valve at BDC. In addition, the Miller cycle presents a better fuel conversion, which results in benefits for efficiency. [5]

Based on the presented ideas, this paper analyses the utilization of Atkinson and Miller cycles in a single cylinder engine. The study is part of a series of recent researches developed by the Mobility Technology Center of UFMG and Robert Bosh Ltda, as an attempt of improving thermal efficiency of internal combustion engines, especially by the combination of different technologies as the variable valve actuation systems. In this way, a numerical methodology has been created for the evaluation of operating conditions with early intake valve closing and a substantial overlapping, which aims the trapping of internal residual gases. The main results from the tridimensional simulation have been validated with experimental data in order to allow any future works with this methodology. Other experimental data from tests in the baseline condition of the engine have also been included in the analysis, permitting a comparison between two conditions differentiated by the utilization of Atkinson and Miller cycles, beyond distinct overlapping times.

\section{METHODOLOGY}

In this section, they are presented the methodologies adopted for running an engine baseline condition and other operation with advanced intake valves timing. Both conditions have been tested experimentally, while only the latter has been evaluated numerically.

\subsection{Experimental methodology}

The chosen condition for the analysis consists of an engine rotation of $2500 \mathrm{rpm}$ and an indicated mean effective pressure of 3 bar, medium values common to driving conditions in a city. The experimental tests were performed in a four valve Single Cylinder Research Engine - SCRE, equipped with a piston suited for port fuel injection and with a volumetric compression ratio of 15:1. Figure 1 shows an image of the engine, while Table 1 presents its main specifications for the baseline condition. 
Table 1. Engine specification (baseline)

\begin{tabular}{|c|c|}
\hline Model & AVL 5496 \\
\hline Type & Single Cylinder \\
\hline Swept volume & $454.16 \mathrm{~cm}^{3}$ \\
\hline Bore & 82 \\
\hline Stroke & 86 \\
\hline Connecting Rod & 144 \\
\hline Compression ratio & $15: 1$ \\
\hline Number of Valves & 4 \\
\hline Exhaust Valve Open & $56^{\circ}(\mathrm{BBDC})$ \\
\hline Exhaust Valve Close & $0^{\circ}(\mathrm{ATDC})$ \\
\hline Inlet Valve Open & $0^{\circ}(\mathrm{BTDC})$ \\
\hline Inlet Valve Close & $40^{\circ}(\mathrm{ABDC})$ \\
\hline Exhaust Valve diameter & $28 \mathrm{~mm}$ \\
\hline Intake Valve diameter & $33.9 \mathrm{~mm}$ \\
\hline
\end{tabular}

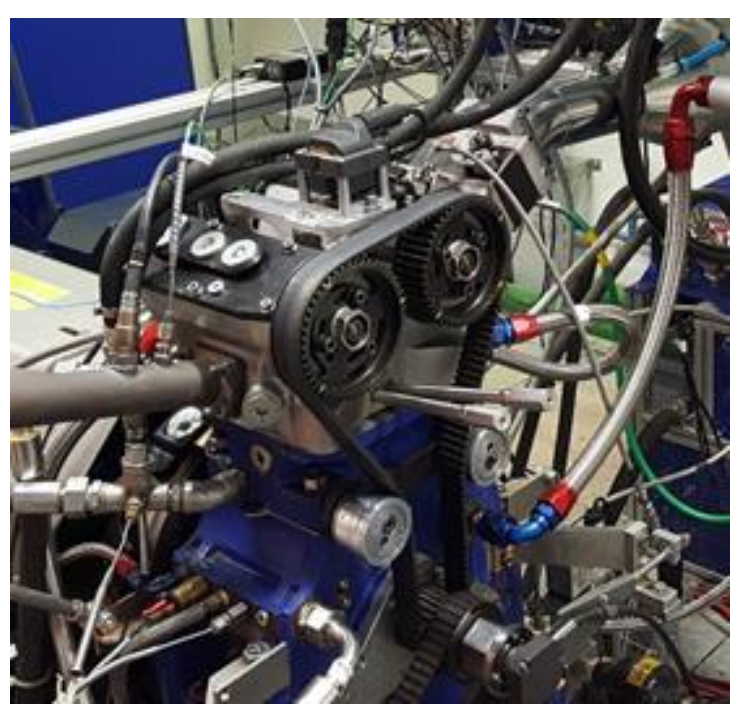

Figure 1. Single cylinder engine

The baseline condition of the engine is characterized by a considerably late intake valve closure time and at the same time by no overlapping. In this way, by closing the exhaust valve and opening the intake valve at the top dead center, it theoretically guarantees a perfect cleaning of the combustion chamber from the burnt gases. In addition to this configuration, another experiment considered the advance of the intake valve timing. Figure 2 presents this change in valve actuation. By advancing it in $49^{\circ}$, one obtains an overlapping with the same duration, while keeping the intake valve closing time anticipated by $9^{\circ}$ before the bottom dead center. With this, it is expected that the upward movement of the piston during the exhaust stroke will force some burnt gases through the admission system, which in turn will come back later into cylinder, characterizing the use of internal residual gases.

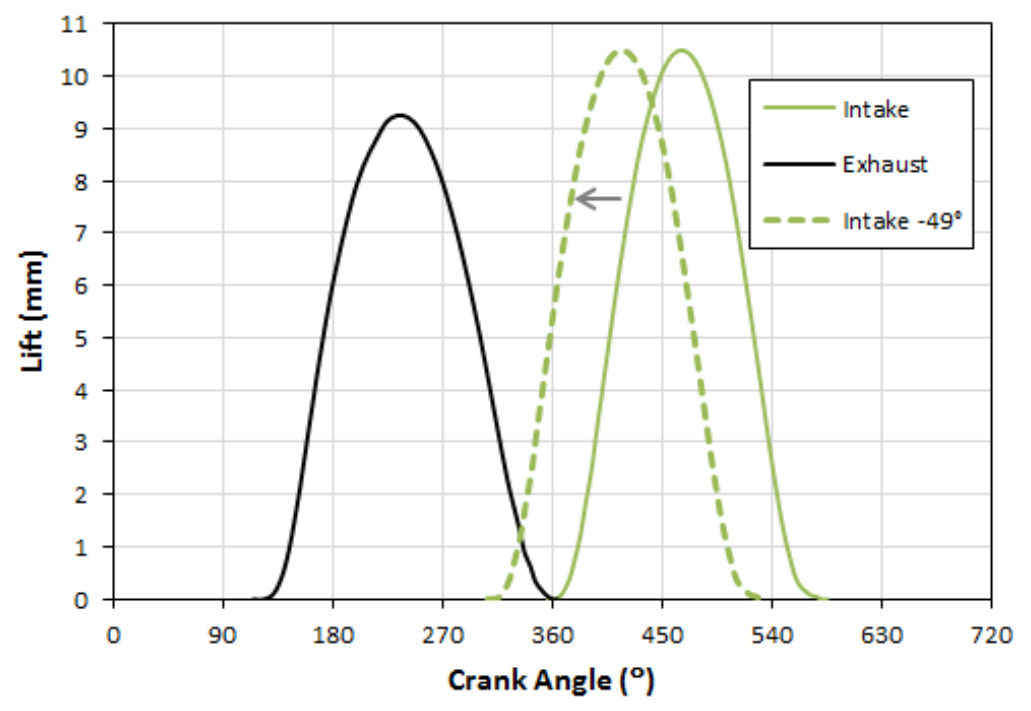

Figure 2: Valve lifts for the baseline condition $\left(0^{\circ} \mathrm{IVO}\right)$ and advanced valves condition $\left(49^{\circ} \mathrm{IVO}\right)$ 
For both tests it was used the port fuel injection, the ethanol (E100) as fuel and an a stoichiometric air-fuel mixture. Table 2 presents some information about this injection. In addition, for both operating conditions $\left(0^{\circ}\right.$ IVO and $49^{\circ}$ IVO) it was employed

Table 2. Port fuel injection information

\begin{tabular}{|l|c|c|}
\hline Operating condition & $0^{\circ}$ IVO & $49^{\circ}$ IVO \\
\hline Start of injection $\left(^{\circ}\right)$ & 181 & -299 \\
Duration of injection $\left(^{\circ}\right)$ & 55.5 & 19.1 \\
Injection pressure $(\mathrm{bar})$ & 4 & 4 \\
Mass flow rate $(\mathrm{kg} / \mathrm{s})$ & 4.5 & 12.8 \\
\hline
\end{tabular}

The monitoring and obtaining of the in-cylinder pressure values were realized by means of the IndiCon acquisition system. The same system was also used for the combustion analysis, by yielding some average data like the mass burned fraction (MBF 10-90\%) and the indicated mean effective pressure covariance (COV-NIMEP), all of them acquired after 200 cycles. For the comparison between these information and the numerical results, it was chosen a representative cycle, by overlapping the mean pressure curve over the 200 cycles until a similar curve was found. Figure 3 exemplifies this procedure, showing the mean pressure curve (in red) being compared with the result from three different cycles (in green). In this example, only the third curve is similar enough and would be used for the comparison.
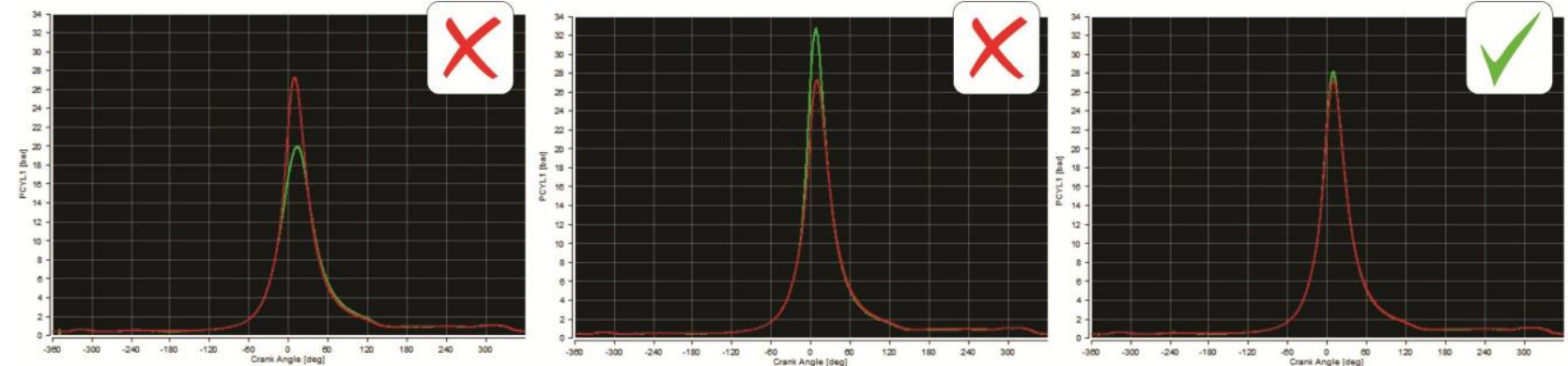

Figure 3: Example of procedure used to select a representative curve from the results of the IndiCon acquisition system.

Another important acquisition system used for experimental data collection was NAPRO, which was utilized for the volume measurement of the four main gaseous pollutants: CO, $\mathrm{CO} 2$, NOx and $\mathrm{HC}$.

\subsection{Numerical methodology}

Tridimensional simulations were performed using STAR-CCM+ and Star-CD code. Starting from the geometry of the engine used in the experiment, it was extracted the internal volume, which corresponds to the volume of the chamber, intake and exhaust ports and manifolds. A hexahedral mesh with a characteristic length of $0.9 \mathrm{~mm}$ was chosen after a sensitivity grid test. At the piston bottom dead center position the mesh presented around 965.000 cells and the intake and exhaust manifold presented around 232.000 and 58.000 cells. Figure 4 shows the mesh of the engine at the bottom dead center position and of the manifolds. 


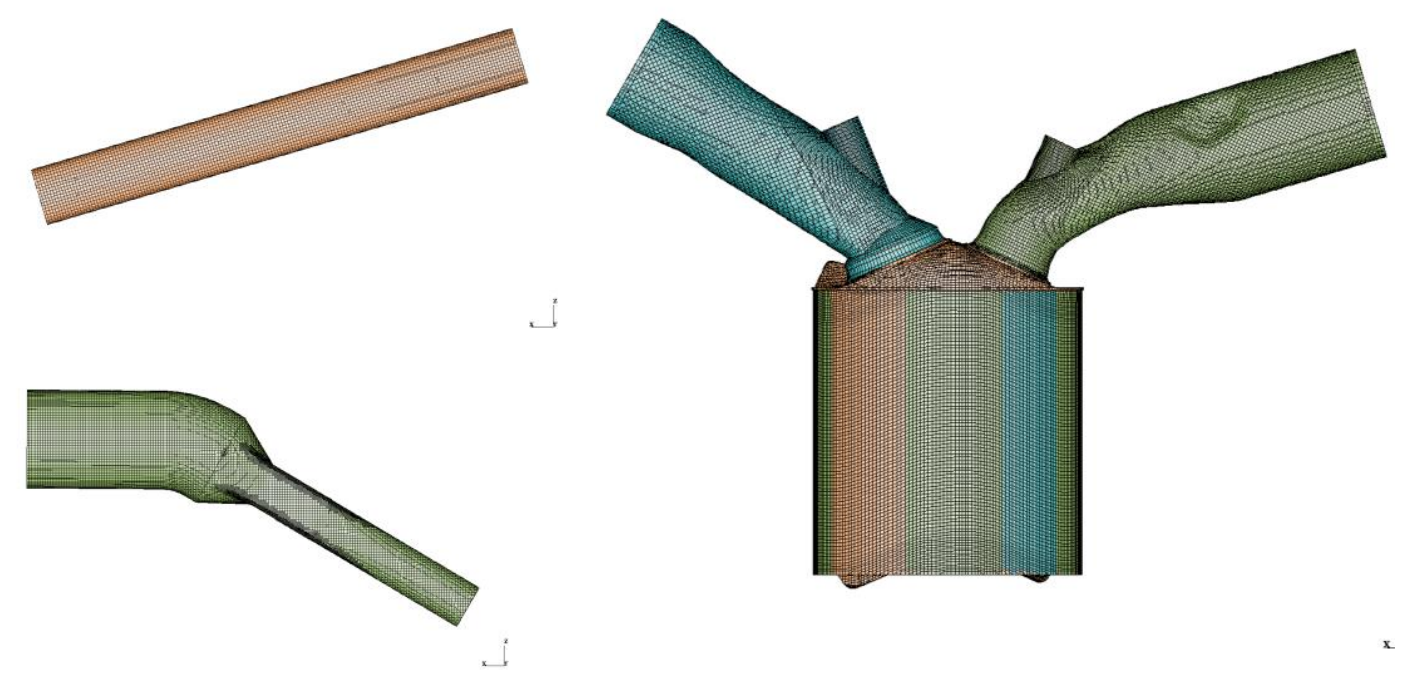

Figure 4: Computational domain and generated meshes used in the 3D simulation.

In the setting of the model, it was considered that the fuel is already mixed with air in the intake. This simplification is considered valid for a PFI operated engine, since the fuel is injected and evaporates in the ports, being almost homogeneously mixed at the moment of the ignition. This assumption was already used with success by Silva et. al [6].

To model turbulence, it was used the Re-Normalization Group (RNG) k- $\varepsilon$ model by Yakhot et. al [7], which is a variation of the k- $\varepsilon$ model where it was added two transport equations, one for turbulent dissipation and one for turbulent kinetic energy.

The combustion model used in this work was the 3 Zones Extended Coherent Flame Model (ECFM-3Z) developed at the Institut Français du Pétrole (IFP) [8, 9]. The model constants $\alpha$ and $\beta$ were set to 1.32 and 1.0 , respectively.

For the boundary conditions it was used the measured pressures and temperatures provided by the experiment. The temperature in the intake manifold was defined as $298 \mathrm{~K}$ and in the exhaust as $820 \mathrm{~K}$. The temperature in the piston head and cylinder head was set $473 \mathrm{~K}$, while in the cylinder wall it was $423 \mathrm{~K}$. The measured pressures used on the intake and exhaust frontiers are shown in the Figure 5.

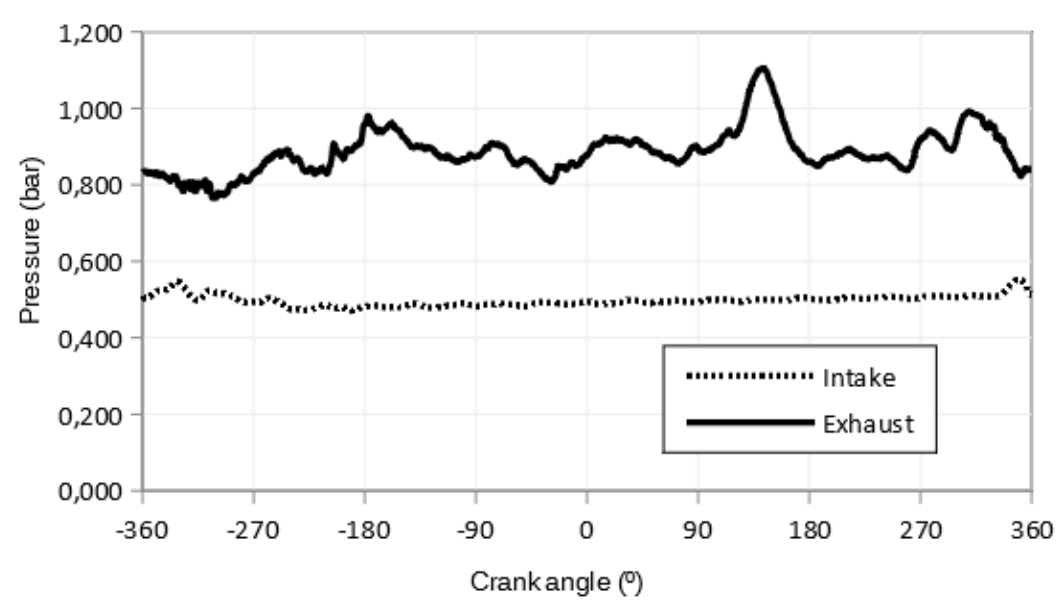

Figure 5: Boundary conditions at the frontiers: intake an exhaust pressures. 
The simulation was started 60 degrees before the intake TDC and run for three full cycles, in order to stabilize the charge flow and get the results only from the last cycle. For the initialization, they were used measured values of pressure from cylinder and intake and exhaust frontiers for this initial crank angle.

It was used a base time-step of 6.7e-06 seconds for the simulation. During the valves opening and closing events and during the valves overllaping time, the time-step was reduced to $3.3 \mathrm{e}-06$ seconds. The convergence criteria was set to 0.001 for all variables.

\subsubsection{EGR quantification}

One of the great advantages of performing numerical simulations is the possibility of analyzing some information not available or difficult to obtain in the experimental tests. For the calculation of the internal EGR from the operations with valves overlapping, for example, the knowledge of the mass fractions of the species can help considerably.

One possible way to calculate residual gases between consecutive cycles is by evaluating the concentrations of carbon dioxide. Many authors have already presented this type of approach, especially for external EGR measurement, by relating the amount of $\mathrm{CO} 2$ in the intake manifold with that in the exhaust manifold [10], [11], [12]. In this paper, the EGR percentage (\%EGR) is defined as:

$\% E G R=\frac{m_{E G R}}{m_{t}} \times 100$

Where $m_{E G R}$ is the mass of residual gases and $m_{t}$ is the total admitted mass. For the calculation of the mass of residual gases, Equation (2) is utilized.

$m_{E G R}=\frac{m_{C O 2}}{x}$

Where $m_{\mathrm{CO}_{2}}$ is the mass of carbon dioxide inside cylinder before combustions starts and $x$ is the theoretical ratio between $\mathrm{CO} 2$ concentration and the other species concentration in the products resulting from combustion process.

\section{RESULTS}

\subsection{Comparison between $0^{\circ}$ IVO and $49^{\circ}$ IVO}

Before showing the numerical results, some data provided by the experiment with the baseline condition $\left(0^{\circ} \mathrm{IVO}\right)$ is compared with those from the operation with advanced valves $\left(49^{\circ} \mathrm{IVO}\right)$.

The first information evaluated was the pumping mean effective pressure (PMEP), shown in Figure 6. The comparison evidences a considerable reduction in pumping losses, when working with advanced admission systems, a clear consequence of the excess of burned mixture and the larger throttle valve opening (de-throttling). 
However, as shown by the same figure, this gain does not prevent a reduction in the fuel conversion efficiency. Larger amounts of fuel are necessary to yield the same fuel-air equivalence ratio and power. In spite of this, as well as specific fuel consumption, this worsening is not substantially high, being about $0.9 \%$.
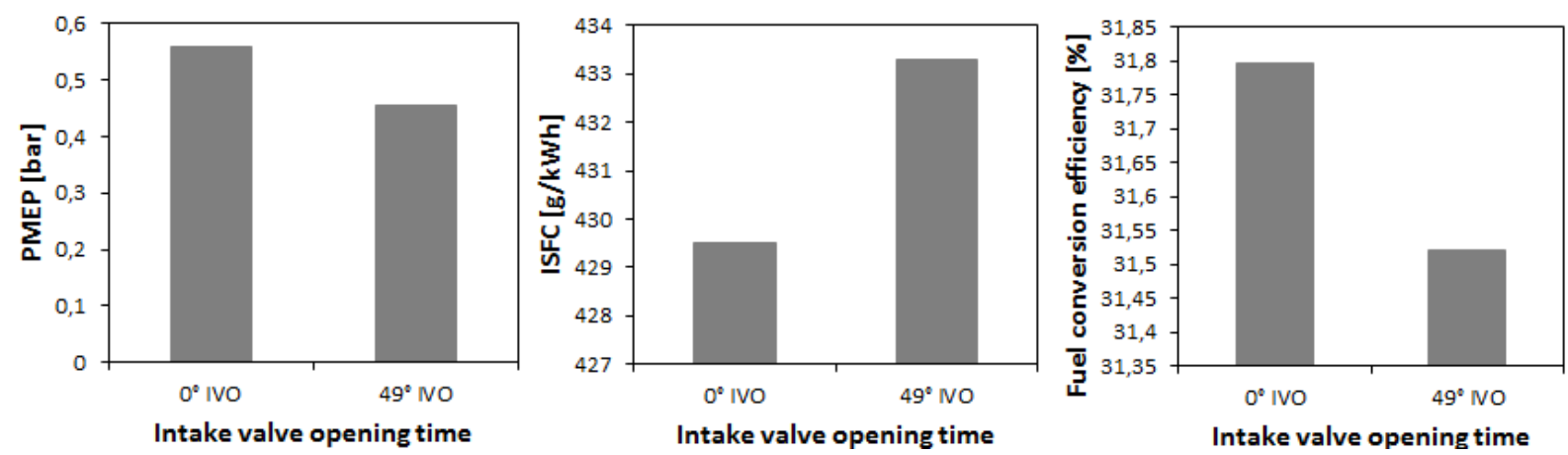

Figure 6: Comparison between baseline condition and ( $0^{\circ}$ IVO) and advanced valves condition $\left(49^{\circ}\right.$ IVO)

Other parameter that may be compared in order to explain these differences is the mass burned fraction, which gives us an idea about the combustion process. Its value, in degrees, for the instants between $10 \%$ and $90 \%$ of burned mass is shown in Figure 7. It is possible to perceive that, when advancing the intake valve opening, the process of kernel formation and flame front propagation is decelerated, as demonstrated by the increase of about $17 \%$ in burning duration. This fact is also verified by looking at the values of spark advance, which shows that the combustion in the $49^{\circ}$ IVO condition has to be initiated many degrees before the baseline condition instant. In this way, this degradation of the combustion process means a decrease in combustion efficiencies and may explain the reduction in fuel conversion efficiency. On the other hand, this slower combustion does not mean an unstable process, as shown by the bar graph of the mean effective pressure covariance. Although there is an increase in the cycle-tocycle variations, its value is not so high as to cause great instabilities.
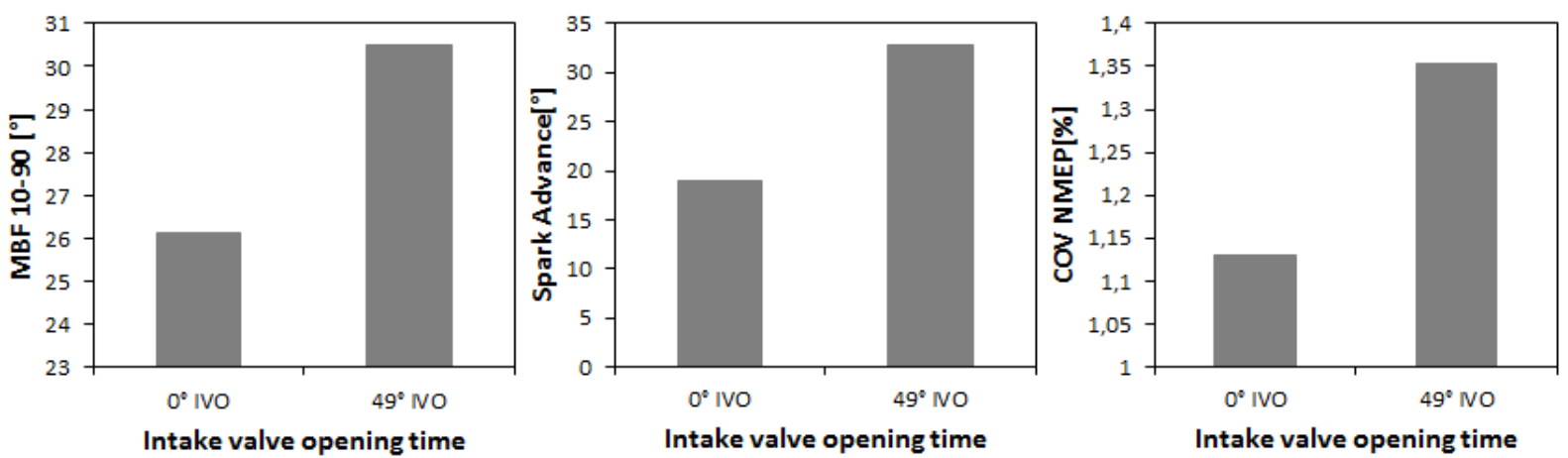

Figure 7: Comparison between baseline condition and $\left(0^{\circ} \mathrm{IVO}\right)$ and advanced valves condition $\left(49^{\circ}\right.$ IVO)

One of the main benefits of operating with advanced intake valves and internal residual gasses is the reduction in gases emissions. Due to the homogenization and the decrease in the average values of temperature in the flame front, the levels of NOx emissions are normally the most affected. As presented in Figure 8, the reduction reaches almost $65 \%$ when using advanced intake valve timing. In a similar way, the 
emissions of $\mathrm{CO}$ and hydrocarbons (HC) also present a considerable reduction, of $34 \%$ and $29 \%$, respectively.
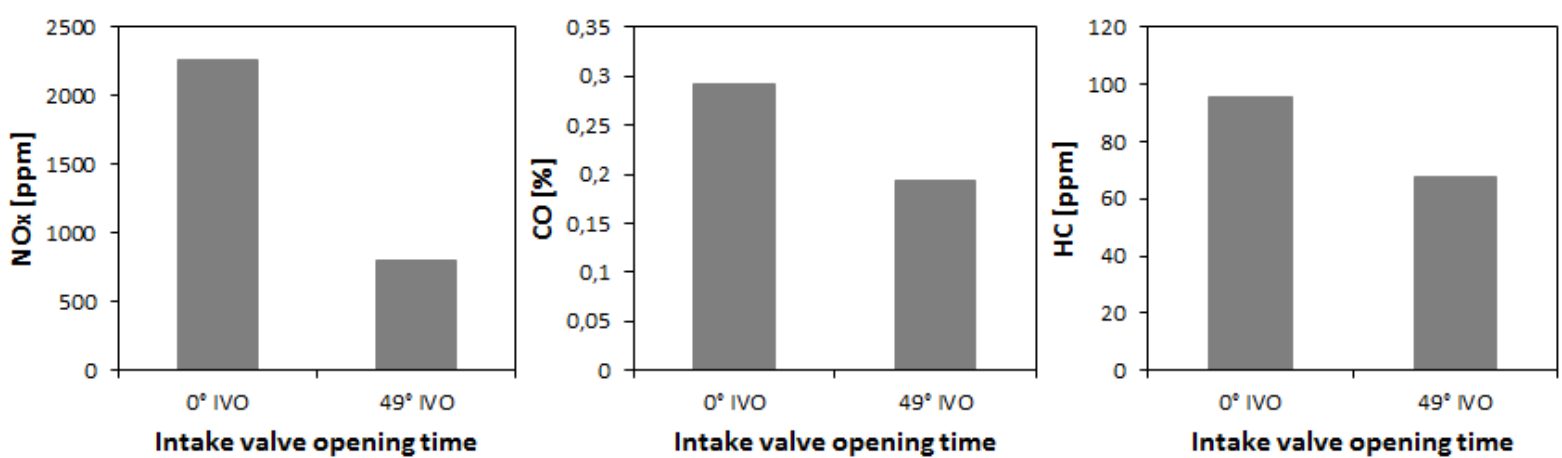

Figure 8: Comparison between baseline condition and ( $0^{\circ}$ IVO) and advanced valves condition $\left(49^{\circ}\right.$ IVO)

\subsection{Numerical results}

In this section, the results provided by the tridimensional simulation of the operating conditions with advanced intake valve timing ( $49^{\circ}$ IVO) are shown and compared with experimental data.

The comparison between in-cylinder pressures is presented in Figure 9, by graphs of pressure versus crank angle and volume. The curves are very similar and the percentage difference between the peak pressure values reaches only $6 \%$. Moreover, the numerical indicated mean effective pressure is about $9 \%$ lower than the expected. By analyzing the variation of pressure with volume, it can be seen a higher deviation during the expansion time. This difference may be associated with the heat losses at the cylinder wall and some assumptions made in the simulation, like fixed temperatures at these walls.
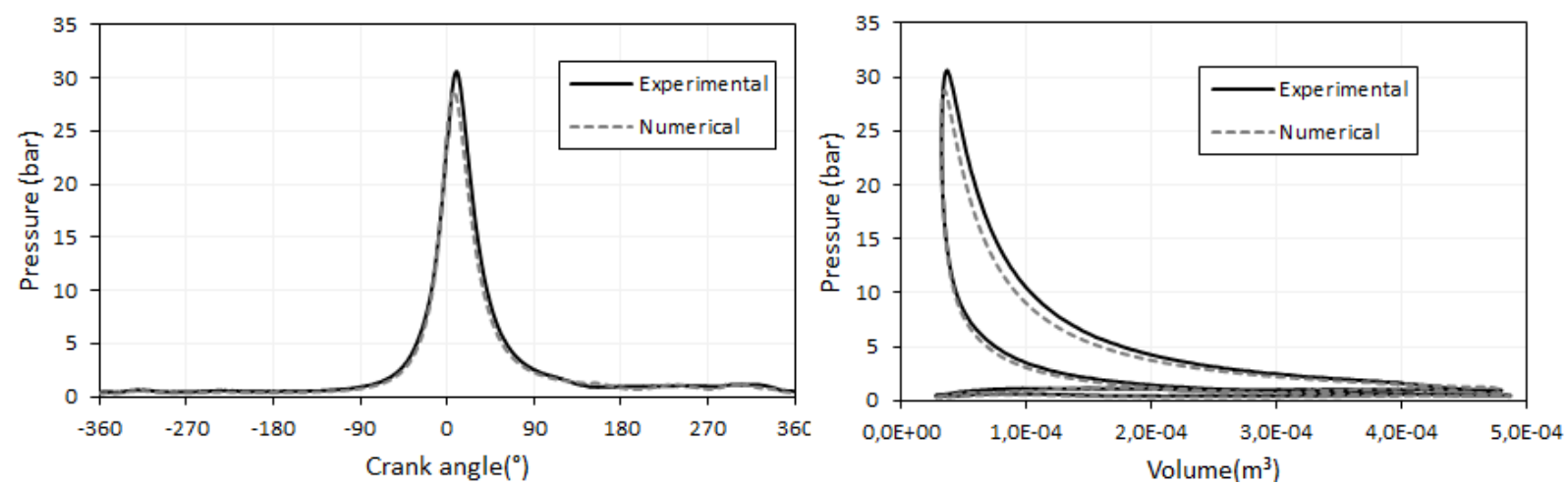

Figure 9: Comparison between numerical and experimental results: advanced valves condition $\left(49^{\circ}\right.$ IVO)

Values of mass burned fraction and heat release rate have also been compared. As shown in Figure 10, these curves present good concordance and small differences. The numerical mass burned fraction for $10 \%-90 \%$ instants is $6.5 \%$ lower than the expected value and the maximum heat release rate of $13.8 \mathrm{~J} /{ }^{\circ}$ is only about $2 \%$ lower than the experimental result. 

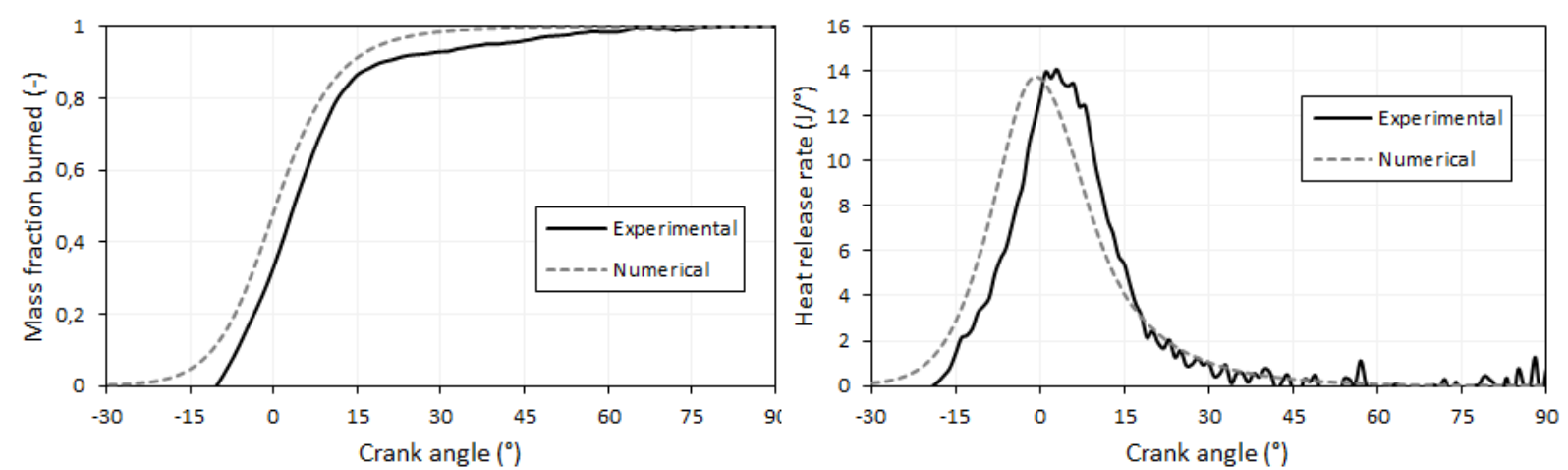

Figure 10: Comparison between numerical and experimental results: advanced valves condition $\left(49^{\circ}\right.$ IVO)

Numerical results of in-cylinder temperatures are also close to expected. Figure 11 presents both experimental and numerical results, with a numerical maximum average cylinder temperature $9.8 \%$ lower than the experimental value. The largest ranges with higher differences are found again during the engine expansion time, reinforcing the possibility of more elevated heat losses being considered in simulation.

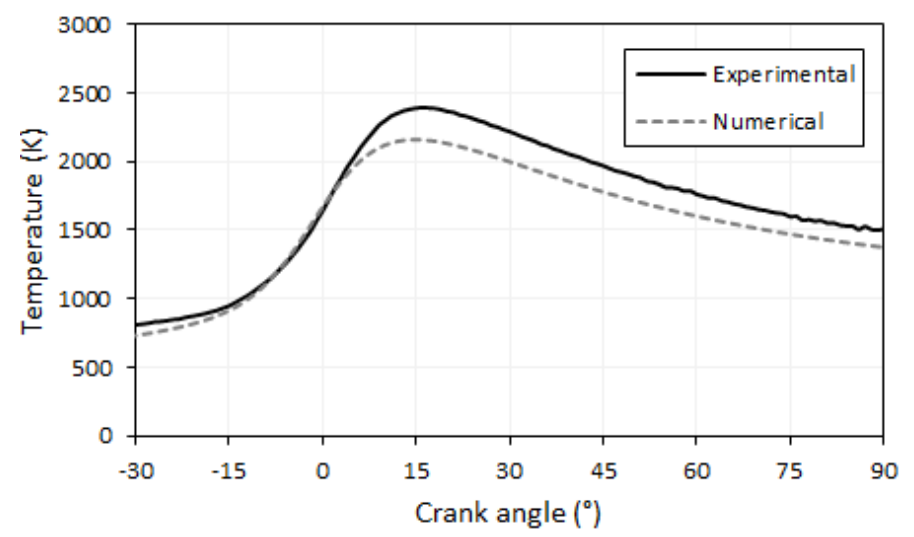

Figure 11: Comparison between numerical and experimental results: advanced valves condition $\left(49^{\circ} \mathrm{IVO}\right)$

Finally, numerical simulation can also be used for the quantification of the residual gas mass inside cylinder, as previously presented in section 1.2.1. Table 3 presents the results of this calculation.

Table 3: Numerical results for internal EGR quantification

\begin{tabular}{|c|c|}
\hline Mass of carbon dioxide trapped & $6.66 \mathrm{mg}$ \\
Residual gas mass & $34.65 \mathrm{mg}$ \\
Total mass admitted & $165 \mathrm{mg}$ \\
EGR percentage & $21 \%$ \\
\hline
\end{tabular}

As can be seen, the internal exhaust gas recirculation, provoked by the advance of intake valve timing, reaches considerable levels of about $21 \%$. This value is consistent with the long duration of the overlapping time and helps to explain the previous results that showed a reduction in flame front propagation speed. An interesting alternative to lead better with these amounts of residual gases could involve the utilization of mechanisms like flow boxes, which could control the air flow through ports and valves, increasing the turbulence and energy inside cylinder. This increase, in turn, 
could improve the mixture formation and accelerate combustion, increasing the efficiencies associated with the burning process and probably reducing specific fuel consumption. Finally, the phenomena of internal residual gasses recirculation can be also verified by analyzing Figures 12 and 13, which present the charge velocities and $\mathrm{CO} 2$ concentration at $10^{\circ} \mathrm{BTDC}$, respectively. Both images show how the mixture really flows back into admission system during the valves overlapping time, carrying part of the residual gases to intake ports.

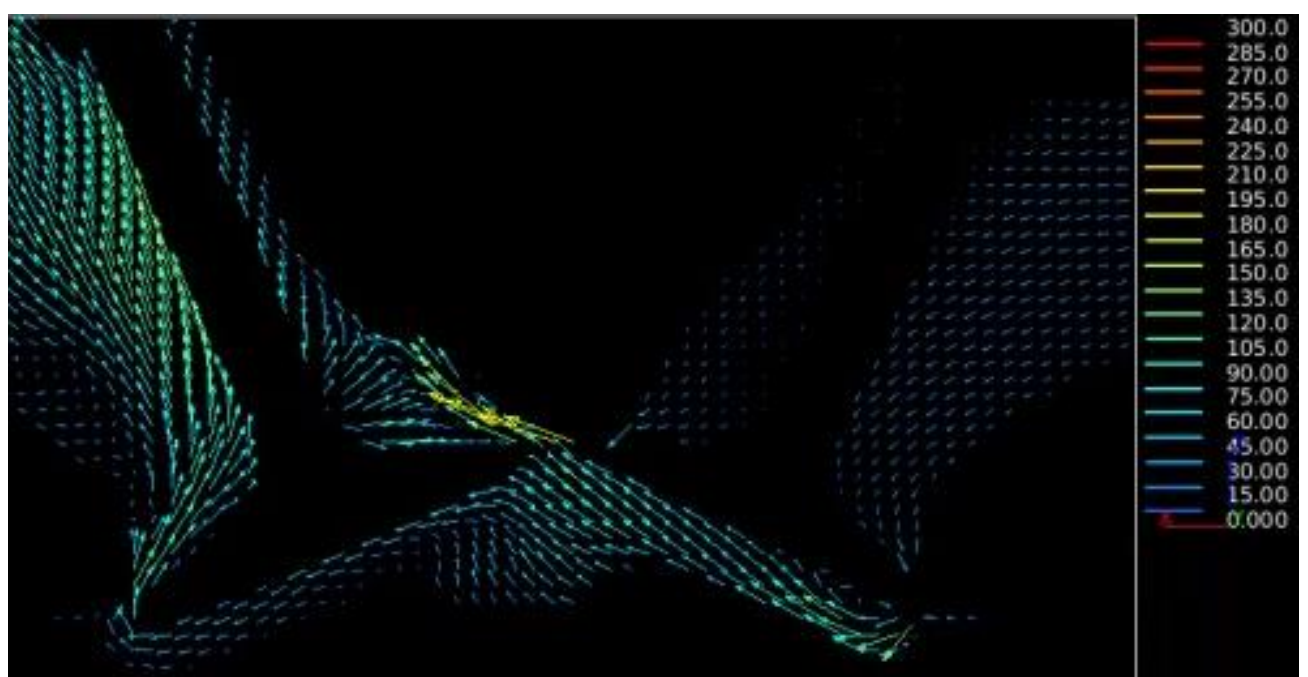

Figure 12: Flow velocities $(\mathrm{m} / \mathrm{s})$ in a section plane passing through the valves at $10^{\circ}$ BTDC: advanced valves condition ( $49^{\circ}$ IVO)

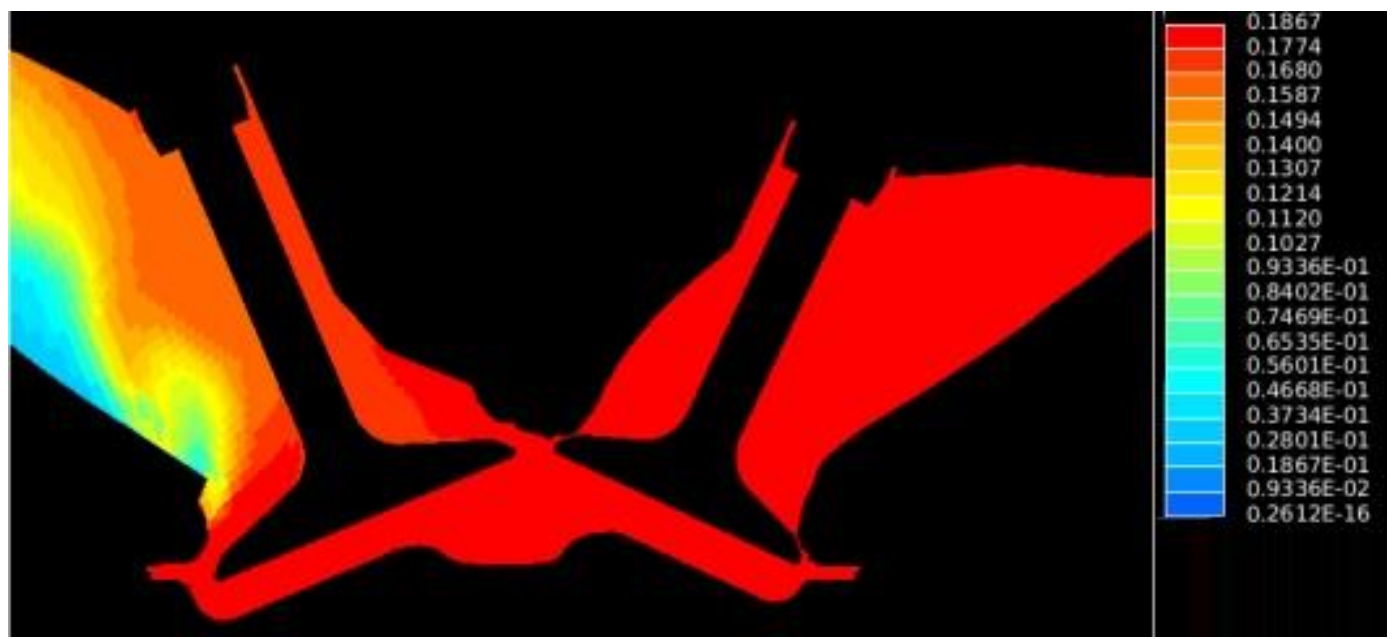

Figure 13: $\mathrm{CO} 2$ concentration in a section plane passing through the valves at $10^{\circ} \mathrm{BTDC}$ : advanced valves condition ( $49^{\circ}$ IVO)

\section{CONCLUSÃO}

In this work, two operating conditions of an engine were analyzed by experimental tests and numerical simulations. A baseline configuration, characterized by late intake valves closing (Atkinson cycle) and no overlapping of the valves, has been compared with a second condition with early intake valves closing (Miller cycle) and considerable overlapping. 
Experimental results evidenced firstly the reduction in pumping losses associated with the dethrottling process, when using early intake valves closing. However, this gain was not followed by improvements in specific fuel consumption and fuel conversion efficiency, which presented a worsening of about $0.9 \%$. These results were associated with the increase in residual gasses trapped inside cylinder and with the decrease in velocities of flame kernel formation and flame front propagation, demonstrated by the $17 \%$ larger burning process duration. On the other hand, these facts did not compromise the stability of the operating cycles. In addition, the use of early intake valves closing with large overlapping reduced all the gasses emissions, especially for NOx. The reductions for NOx, $\mathrm{CO}$ and $\mathrm{HC}$ species were about $65 \%, 34 \%$ and $29 \%$, respectively.

A numerical methodology has also been developed for the analysis of operating conditions with early intake valves closing and substantial overlapping. This methodology has been validated by means of the comparison of different results with experimental data, like incylinder peak values, indicated mean effective pressure, mass burned fraction, heat release rates and in-cylinder temperatures. All these parameters showed differences less than $10 \%$. In addition, the numerical analysis allowed the quantification of the internal residual gasses as being about $21 \%$. Finally, it was proposed as an alternative for improvement of combustion features the adoption of mechanisms for increasing the in-cylinder turbulence, which could allow the obtaining of better efficiencies.

\section{REFERÊNCIAS}

[1] Cordier, M., Laget, O., Duffour, F., Gautrot, X. et al., "Increasing Modern Spark Ignition Engine Efficiency: A Comprehension Study of High CR and Atkinson Cycle," SAE Technical Paper 2016-01-2172, 2016, doi:10.4271/2016-01-2172.

[2] Murata, Yutaka, et al. "Miller-PCCI combustion in an HSDI diesel engine with VVT." SAE International Journal of Engines 1.2008-01-0644 (2008): 444-456.

[3] Hara, Seinosuke, et al. "Variable valve actuation systems for environmentally friendly engines." Hitachi Review 58.7 (2009): 319-324.

[4] Wan Y, Du A. Reducing part load pumping loss and improving thermal efficiency through high compression ratio over-expanded cycle. SAE Paper 2013-01-1744.

[5] Trevas, Igor, et al. Combustion Analysis on a Variable Valve Actuation Spark Ignition Engine Operating With E22 and E100. No. 2017-01-1069. SAE Technical Paper, 2017.

[6] Knop, Vincent, and Leonardo Mattioli. "An analysis of limits for part load efficiency improvement with VVA devices." Energy Conversion and Management 105 (2015): 10061016.

[7] Scheidt M, Brands C, Kratzsch M, Günther M. Combined Miller/Atkinson strategy for future downsizing concepts. Motortech Z 2014;75:4-10

[8] Béard, P., Colin, O. and Miche, M., "Improved Modelling of DI Diesel Engines Using Sub-grid Descriptions of Spray and Combustion”, SAE Paper 2003-01-0008, 2003. 
[9] O. Colin, A. Benkenida, "3-Zones Extended Coherent Flame Model (ECFM3Z) for Computing Premixed/Diffusion Combustion", Oil \& Gas Science and Technology - Rev. IFP vol. 59, issue 6, p. 593-609, 2004.

[10] Saravanan, S., Kumar, B., "Effect of exhaust gas recirculation (EGR) on performance and emissions of a constant speed DI diesel engine fueled with pentanol/diesel blends." Fuel 160 (2015): 217-226.

[11] Abd-Alla, Gamal Hassan. "Using exhaust gas recirculation in internal combustion engines: a review." Energy Conversion and Management 43.8 (2002): 1027-1042.

[12] Wei, Haiqiao, et al. "Gasoline engine exhaust gas recirculation-a review." Applied Energy 99 (2012): 534-544. 